\title{
Observations of Corona Point Discharges from Grounded Rods Under Thunderstorms
}

\author{
Marcelo Arcanjo ${ }^{\text {a, b, * , Joan Montanyà a , Michele Urbani }}{ }^{a}$, Victor Lorenzo ${ }^{\text {b }}$, Nicolau Pineda ${ }^{\text {a, c }}$ \\ a Lightning Research Group, Technical University of Catalonia, TR1, Carrer Colom 1, Terrassa, 08222, Spain; \\ b Dena Desarrollos S.L. (Ingesco), Carrer Cardener 5, Terrassa, 08223, Spain; \\ c Meteorological Service of Catalonia, Carrer Berlín 38-46, 08029, Barcelona, Spain. \\ * Correspondence: marcelo.augusto.sousa@upc.edu;
}

Pre-print of paper published with: https://doi.org/10.1016/j.atmosres.2020.105238

\begin{abstract}
We investigated features of corona point discharges when a grounded conductive rod is subject to a high background electric field. In the laboratory, high voltage is applied to an upper plate in a plane-to-point experiment, and the discharges are observed from a grounded rod using an ultraviolet camera and a photosensor. The current is measured using a shunt resistor, a current transformer, and a high impedance ammeter. We have found that corona current pulses have fast rise time (tens of nanoseconds) and slow decay (hundreds of nanoseconds). For the initial stage of the discharges, above a certain threshold, the frequency of pulses increases with the voltage applied. In the field, one current sensor coupled to a grounded rod, $1.5 \mathrm{~m}$ above a roof, was installed in a site located at an altitude of $2525 \mathrm{~m}$ above sea level. The same pulses observed in the laboratory are recorded during periods of electric field enhancement caused by the movement of charged clouds or lightning activity near the sensor. For that specific installation, the frequency of pulses is correlated with the ambient electric field measured 250 meters away. To the best knowledge of the authors, this is the first time in which such correlation is made for outdoor measurements, seeing that other works correlate the electric field with the average current flow. Pulses of positive corona were no longer observed when the electric field magnitude was lower than $1.8 \mathrm{kV} / \mathrm{m}$ and pulses of negative corona were more atypical and presented a higher threshold, of about $3.8 \mathrm{kV} / \mathrm{m}$. This study is relevant for understanding the production of corona and space charges in high structures, such as wind turbine blades, towers, and buildings in general.
\end{abstract}

Keywords: corona discharge; point discharge; Trichel pulses; electric field; space charge; lightning protection.

\section{Introduction}

Electrodes or structures subject to high electric fields are likely to favor the ionization of air molecules near their tips and edges, where the local electric field is higher, inducing corona discharges (Moreau et al., 2018). The enhancement of the electric field near sharp grounded structures can generate ions and form a space charge layer that ultimately decreases the magnitude of the electric field at the ground level (Kip, 1938; Chang et al., 1991; Chauzy and Raizonville, 1982).

The discharge current through an insulated point in the field was recorded by Whipple and Scrase (1936). They found an empirical relationship in which the magnitude of the downward current is in the order of a few microamperes and is proportional to the squared electric field. In the following years, several other researchers observed a similar relationship (i.e. Hutchinson, 1951; Chapman, 1955), assessing the increase of the corona current caused by the wind. 
Typically, grounded structures can be subject to currents ranging from extremely low values to kiloamperes (as in the case of lightning strikes). A study of discharge currents associated with kite balloons, performed by Davis and Standring (1947), showed that currents ranging from milliamperes to kiloamperes were associated with thundery weather. Chauzy and Soula (1999) simulated the contribution of the point discharges to the convective charging mechanism of thunderclouds. D'Alessandro (2009) conducted a more recent study on corona discharges from a sharp point under a thunderstorm, finding an average current of a few microamperes and electric field thresholds of about $0.5 \mathrm{kV} / \mathrm{m}$ to $1.5 \mathrm{kV} / \mathrm{m}$. His experimental data indicated that higher wind speeds may lead to an increase in the average corona current, and a decrease in the electric field threshold for corona onset. Notably, other than the electric field enhancement, the height of the grounded rod and its shape play a considerable role in the corona current generation (Hutchinson, 1951; D'Alessandro, 2009).

The space charge layer created by corona at ground level can attenuate the electric field in the vicinities of grounded conductors. This can affect the initiation of upward leaders and even change the point of lightning impacts (Aleksandrov et al., 2001; Becerra et al., 2007; Bazelyan, 2015; Guo and Zhang, 2017). Investigations have indicated that the corona layer could delay the streamer inception from structures, although this would not cause severe effects, since the lateral development of upward connecting leaders is not strongly influenced by the glow corona space charge (Becerra, 2013 and 2014). In elevated rotating structures, such as wind turbines, observations suggested that the movement of these structures avoids the shielding effect caused by space charges, increasing the probability of lightning strikes (Montanyà et al., 2014). In the case of cloud-to-ground lightning, approaching downward leaders also lead to the rapid enhancement of the electric field and induced currents in grounded structures (Rakov, 2016; Guimaraes et al., 2017; Arcanjo et al., 2019).

Studies conducted in laboratory have shown the different regimes of corona discharges in a gap. In positive corona, the initial stage is a pulsating regime known as burst pulse corona (Chang et al., 1991). As the electric field increases further, the phenomenon reaches a pulseless stage named glow corona, in which the accumulation of space charges leads to a steady-state uniform corona glow around the needle electrode. For an even higher electric field, intense onset streamers develop, constituting a new region called breakdown streamer. These streamers can create an unstable region that can ionize the entire gap and trigger a spark discharge (Trichel, 1939; Gallo, 1977; Chang et al., 1991). In negative corona, the pulsating regime of the initial stage is known as Trichel Pulse corona (Trichel, 1938). A pulseless stage can develop when the electric field is increased, and the pulses are superimposed one into another. This stage can be unstable at normal temperature and pressure conditions and the discharge can rapidly evolve to a spark (Chang et al., 1991).

Different configurations based on the electrode geometries have been used to perform experiments, the most common being point-to-plane (e.g. Trichel, 1938 and 1939; Gallo, 1977; Dordizadeh et al., 2015). In these cases, the high voltage electrode is typically a needle and the second electrode is a plate grounded through a shunt resistor. The so-called corona current is the current measured through the resistor. For the initial stages of corona discharge (burst corona and Trichel pulse corona), the current is observed as a regular train of pulses with a short rise time (tens of nanoseconds), and time decay in the order of few hundreds of nanoseconds and rather long inter-pulse time (a few microseconds to milliseconds), depending on the configuration of electrodes and the voltage applied (Dordizadeh et al., 2015; Wang et al., 2018).

This work comprises experiments with grounded conductors with sharp tips under high background electric fields. In the laboratory, they are inserted between a grounded plate and an upper plate with a DC high voltage applied. In the field, the rod is installed over a roof, and exposed to thunderstorm conditions. Features of the corona current in both cases are assessed and discussed.

\section{Methodology and instrumentation}

In the laboratory, two approaches were used to measure the corona current: a current transformer and a shunt resistor. Figure 1 shows a diagram of the connections of the two sensors to the rod within the setup. 


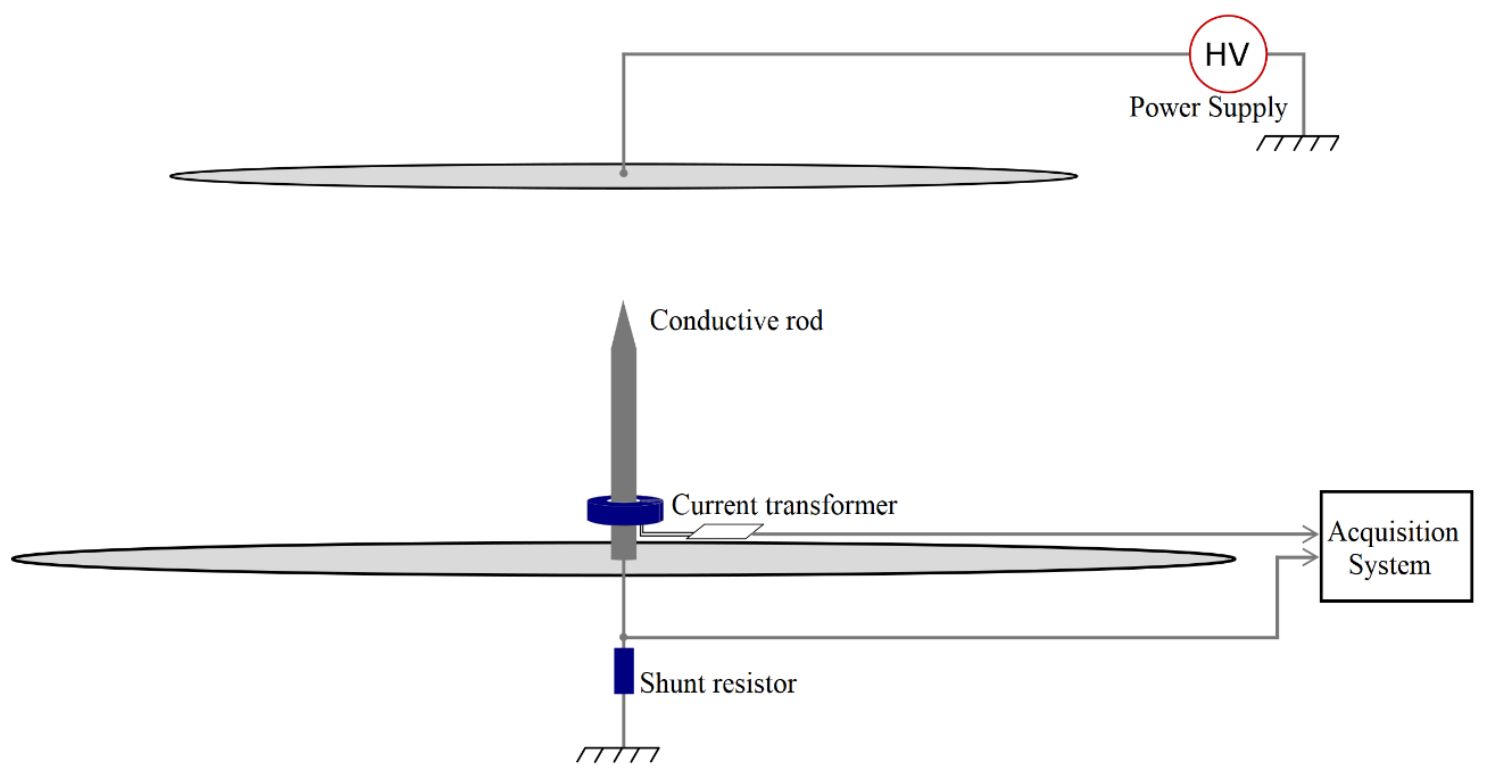

Figure 1. Conductive sharp rod in the plane-to-point setup.

The experiments were performed using a grounded conductive rod of $80 \mathrm{~cm}$, placed between two plates (with $1.4 \mathrm{~m}$ and $2.0 \mathrm{~m}$ of diameter) separated by $100 \mathrm{~cm}$, leading to a gap distance of $20 \mathrm{~cm}$. The high voltage power supply provides up to $20 \mathrm{kV}$ DC at positive or negative polarity, and it is connected to the upper plate. The bottom plate is grounded through the resistor. This setup reproduces the conditions of sharp grounded structures that are subject to high electric fields when charged clouds are in the vicinity, in such a way, corona emissions are expected from the tip of the rod.

The shunt resistor affects significantly the shape of the waveform, since current pulses are very fast, with a rise time of tens of nanoseconds and decay of a few hundreds of nanoseconds (e.g. Kexin et al., 2015; Wang et al., 2017; Dordizadeh et al., 2017; Wang et al., 2018). If higher values of resistors are used, current pulses have a longer duration. Hence, a resistor with low inductance and low resistance is required. We used a 50-ohm shunt resistor for the characterization of the corona pulse, and after that, the resistor was substituted by an ultralow-current ammeter that measures the average DC current flow through the grounding cable. The current transformer does not affect the circuit to be measured, and it is composed of a ferrite core with a secondary winding and an auxiliary circuit. Its inductance is $101 \mu \mathrm{H}$, and the circuit has cutoff frequencies of $35 \mathrm{kHz}$ and $20 \mathrm{MHz}$. Within the bandwidth, the circuit presents a flat response and the output voltage is proportional to the current flow through the rod, with a voltage ratio of about $12.3 \mathrm{~V} / \mathrm{A}$.

Two optical systems were used for performing detections. Using a low-speed camera with an intensifier for the UV and near-blue range $(275-375 \mathrm{~nm})$ it was possible to visualize corona discharges. A secondary system consists of an optical fiber cable pointing to the tip of the rod (as seen in Figure 2) coupled to a filter centered at $375 \mathrm{~nm}$ (20 nm bandwidth) and connected to a photosensor tube. The electrical signals emitted by the photosensor correspond to an optical signature of the discharge. Using both systems it was possible to ensure that the signals measured by the photosensor were related to the tip of the rod and not with corona from the tip of the optical fiber. 


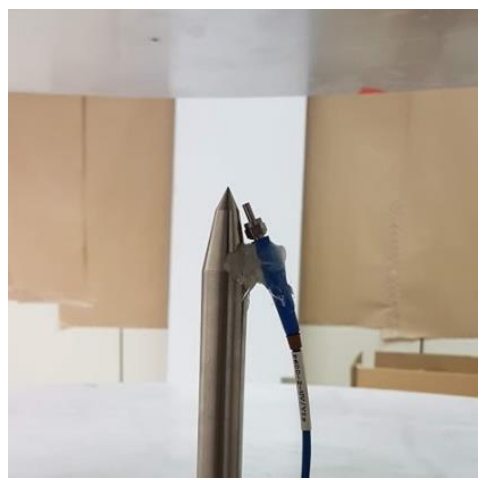

Figure 2. Picture of the optical fiber pointing to the tip of the rod.

In section 3, we show the results of a set of experiments in the laboratory, measuring the corona current with the different probes, increasing the voltage applied to the plate. The amplitude and frequency of the pulses are assessed and synchronized with optical detections.

In section 4, we conduct experiments in the field with a current-transformer prototype. Data records were correlated with the background electric field. This measurement was performed employing a calibrated Electric Field Mill with a 10-Hz time resolution and a form factor adjusted considering waveforms correspondent to fair-weather days compared to the well-known Carnegie Curve (Harrison, 2013). We adopted, by convention, to present the values of the gradient of the electric potential, that correspond to the negative of the electric field vertical component.

We used data of a stand-alone VHF interferometer (Montanyà et al., 2012; Pineda et al., 2018) located at a few kilometers of the sensor, in order to track lightning evolution in the vicinity of the site of installation. We verified the LINET lightning detection network for mapping both intra-cloud and cloud-to-ground lightning strikes during the events analyzed. Wind measurements were gathered by the nearby Tosa d'Alp Automatic Weather Station (AWS), part of the Meteorological Service of Catalonia (SMC) network.

\section{Features of positive and negative corona point discharges}

The shape of one single pulse is shown in Figure 3 when the upper voltage is $-16 \mathrm{kV}$, leading to positive corona (a), and $+16 \mathrm{kV}$, leading to negative corona (b). The signals were digitized at a sampling rate of $2.5 \mathrm{GHz}$ with a bandwidth of $500 \mathrm{MHz}$. The measurements obtained with the shunt resistor and the current transformer are correlated by applying the V/A ratio (of 12.3) for the current transformer.

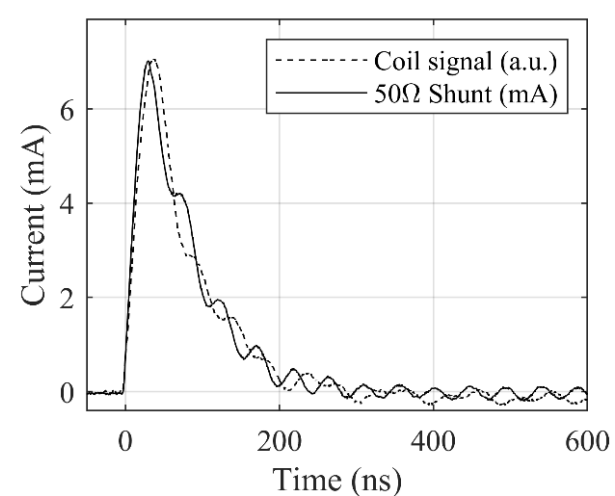

(a)

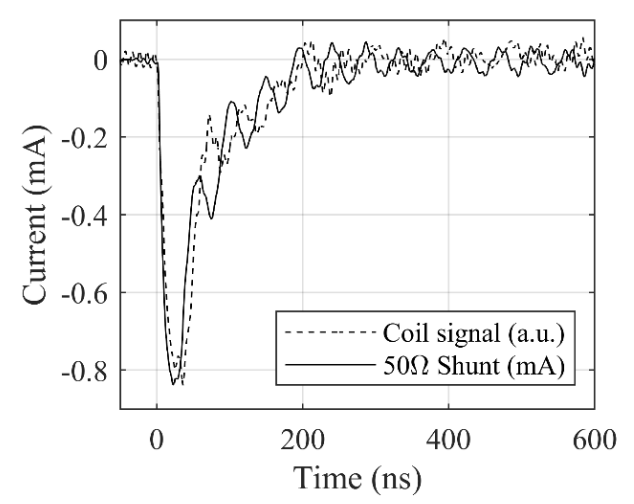

(b)

Figure 3. Typical corona pulse waveform measured with shunt resistor and current transformer.

(a) Positive corona; (b) Negative corona. 
Table 1 presents the rise and decay times of the corona pulses depicted in Figure 3. These parameters do not change significantly with changes for the applied voltage, while their peak amplitude can change considerably even for the same applied voltage. For $16 \mathrm{kV}$, negative corona pulses (Trichel Pulses) are faster than positive corona bursts, and the amplitude of them is about one order of magnitude lower. The tail of the waveform of the pulses exhibits small oscillations that may be caused by reflections of the fast-current wave in the measuring instrument.

Table 1. Corona current pulse (-16 kV / $+16 \mathrm{kV}$ applied)

\begin{tabular}{cccc}
\hline & $\begin{array}{c}\text { Rise time } \\
(\mathbf{n s})\end{array}$ & $\begin{array}{c}\text { Decay time } \\
(\mathbf{n s})\end{array}$ & $\begin{array}{c}\text { Average peak amplitude } \\
(\mathbf{m A})\end{array}$ \\
\hline Positive corona pulse & 30 & 400 & 7.0 \\
Negative corona pulse & 20 & 300 & 0.8 \\
\hline
\end{tabular}

\subsection{Optical Detections}

Using the current transformer, corona pulses are synchronized with optical detections measured by a photosensor, as shown in Figure 4. The pulse shape of the optical detection presents an oscillating behavior and low amplitude. Its time duration is compatible with the current pulse.
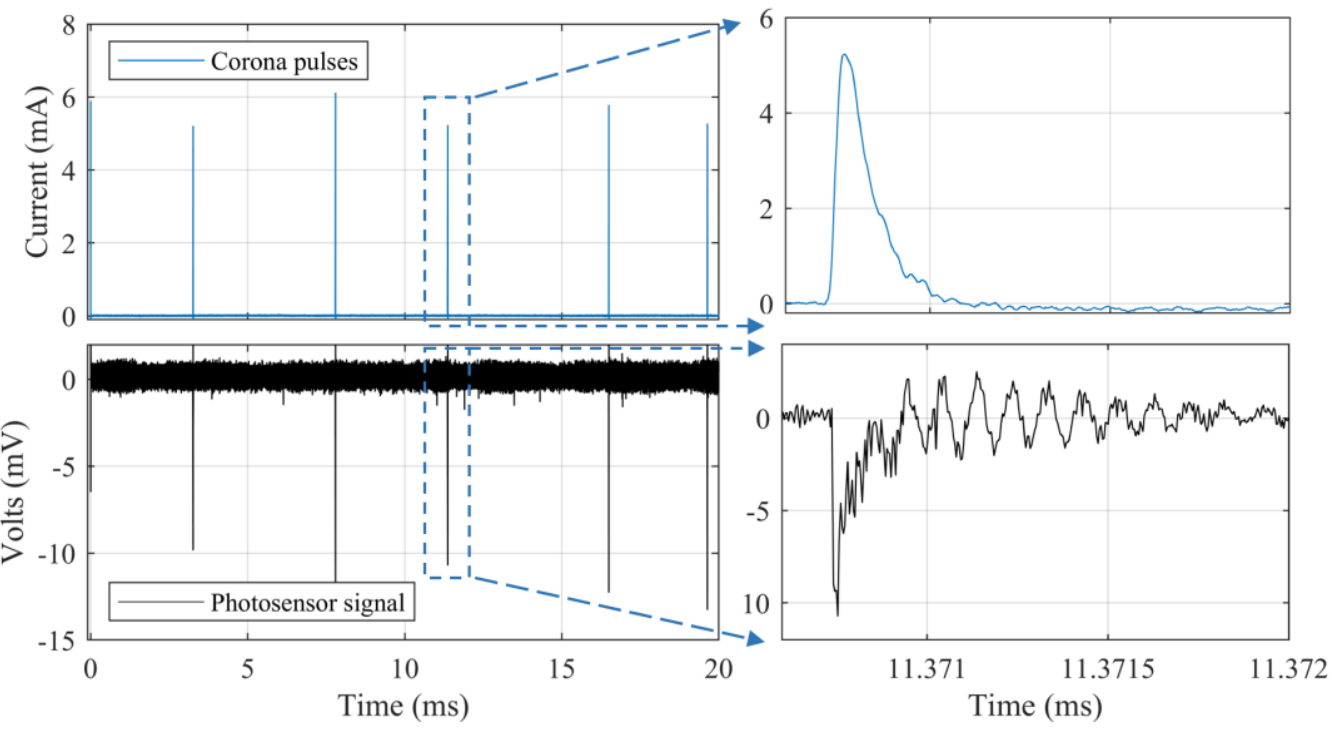

Figure 4. Optical detections synchronized with corona current for $-15 \mathrm{kV}$ applied in the upper plate.

Figure 5 depicts a picture of the rod taken with the UV-camera when the applied voltage is $16 \mathrm{kV}$ for each of both polarities. The camera is placed at $1.3 \mathrm{~m}$ far from the tip of the rod, at the same height. The images were processed to enhance and color the corona region. One can note that the positive corona develops filamentary streamers of around $1.7 \mathrm{~cm}$, while, for the same voltage applied, the negative corona is seen as a glow above the tip of the rod, with a non-clear size. 

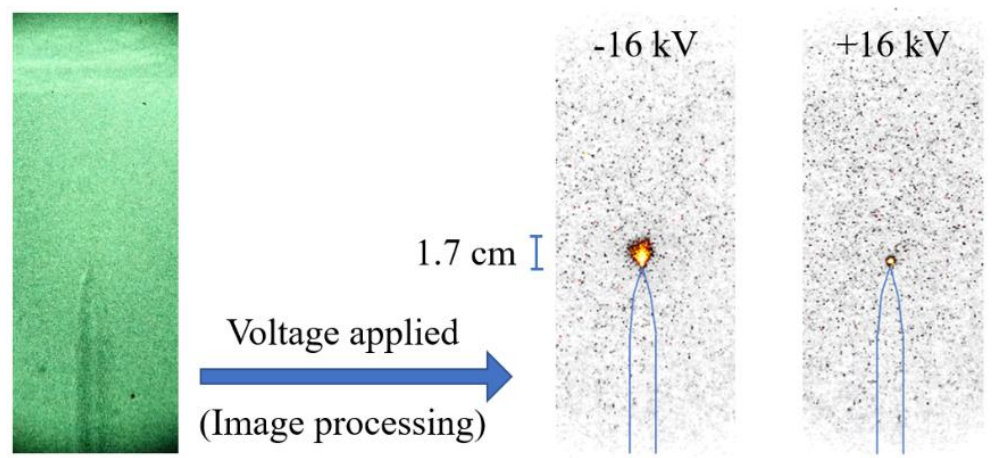

Figure 5. Picture of corona discharges from the rod after image processing.

\subsection{Negative corona pulses}

The experiments described in sections 3.2 and 3.3 were performed in a room temperature of 20.7 degrees Celsius, pressure of $980 \mathrm{mbar}$ and humidity of $49 \%$. We replaced the shunt resistor used in the setup shown in Figure 1 by a high impedance ammeter with a low sampling frequency $(4 \mathrm{~Hz})$ to measure the average corona current. We used the current transformer to measure the pulse frequency, recording a time window of one second. For each voltage applied, five separate experiments were made, and then we calculate the average current and average pulse frequency obtained. Thereby, we were monitoring simultaneously the upper plate voltage, the average current, and the pulse frequency.

Negative corona is obtained when positive voltage is applied on the upper plate. Figure 6 shows the frequency of pulses detected according to the voltage. For the range of voltages applied in the setup described in section 2, the inception voltage for corona was $8.2 \mathrm{kV}$. The average current and the pulse frequency increase with the increase of the applied voltage, reaching $6 \mu \mathrm{A}$ and $35 \mathrm{kHz}$, respectively, at $18 \mathrm{kV}$. Closer to the inception voltage, we applied many different voltages in the range from $8 \mathrm{kV}$ to $9 \mathrm{kV}$. Both the average current and the pulse frequency curves present a knee shape-like rising considerably after the inception.

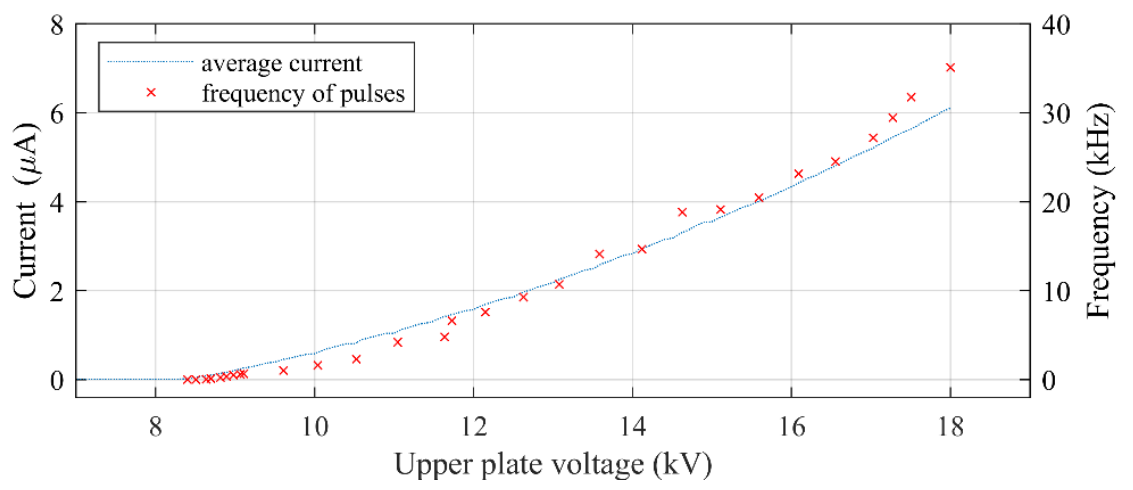

Figure 6. Average current (absolute value) and frequency of negative corona pulses.

Figure 7 depicts an interval of 10 milliseconds showing negative corona pulses for an upper plate voltage varying from 9 to $18 \mathrm{kV}$. We observed considerable dispersion in the amplitude of the pulses. The current peaks reach milliamperes, which is substantially higher than the average current, in the few microamperes range. Visually, using the ultraviolet camera, the shape of the discharges does not change compared to that observed in Figure 5, being a tiny glowing spot with a slight increase of intensity for higher voltages. 


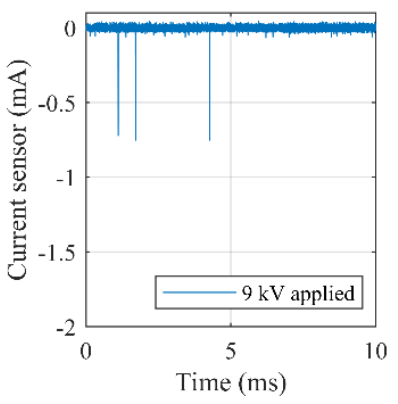

(a)

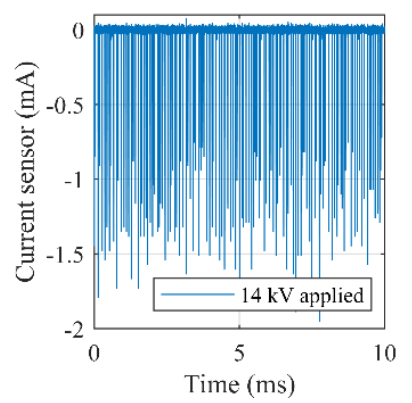

(b)

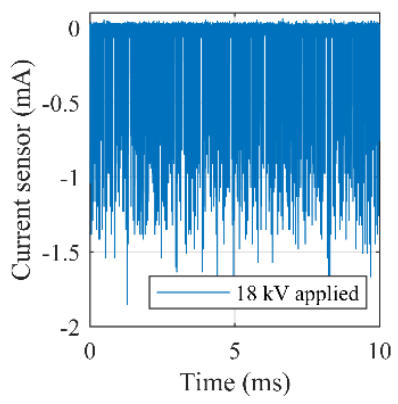

(c)

Figure 7. Negative corona pulses in a 10-ms time window. (a) $9 \mathrm{kV}$; (b) $14 \mathrm{kV}$ (c) $18 \mathrm{kV}$.

\subsection{Positive corona pulses}

Using the same setup for studying positive corona from the conductive rod, we observed a different behavior of average current and frequency. Figure 8 illustrates how these variables change as the upper plate voltage increases in magnitude. The voltage for inception detected was $-9.9 \mathrm{kV}$. Initially, as the voltage increases, the frequency and current increase, but at around $-14.5 \mathrm{kV}$ the frequency reaches a maximum and the current has a slight decrease. Higher voltages cause a decrease in the frequency of pulses until they ultimately disappear at $-19 \mathrm{kV}$, nevertheless, the average current persists to increase, up to a few microamps, reaching similar values to the case of negative corona, and indicating that the discharge has not ceased.

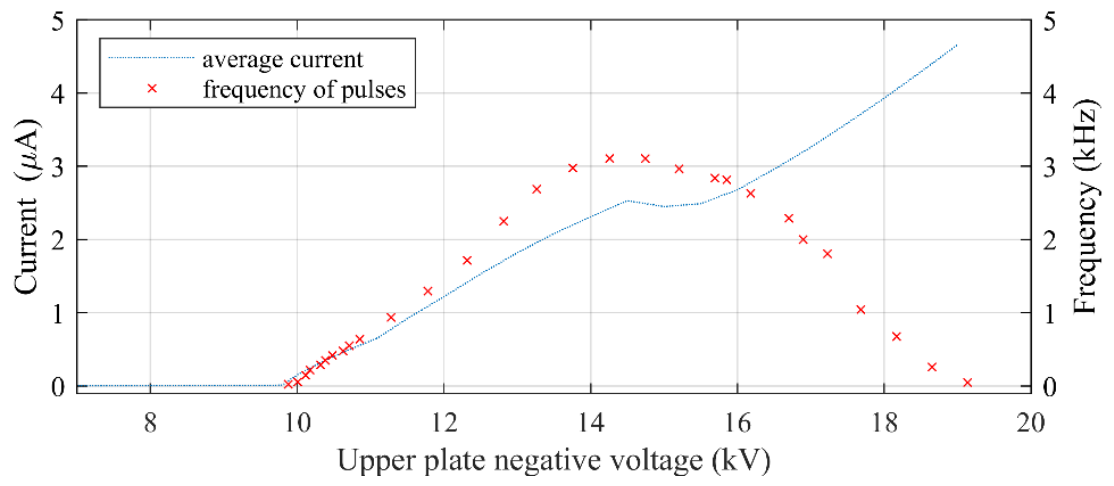

Figure 8. Average current and frequency of positive corona pulses.

The behavior of burst pulses observed for positive corona is shown in Figure 9, in a longer time window than the one shown in Figure 7, due to the lower values of pulse frequency for this case. The maximum frequency obtained for the given setup is equal to $3.2 \mathrm{kHz}$.

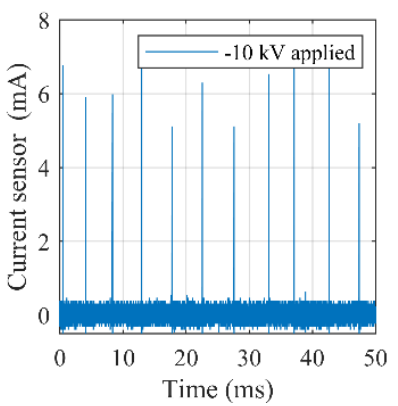

(a)

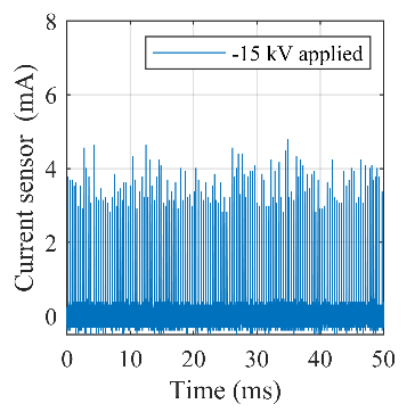

(b)

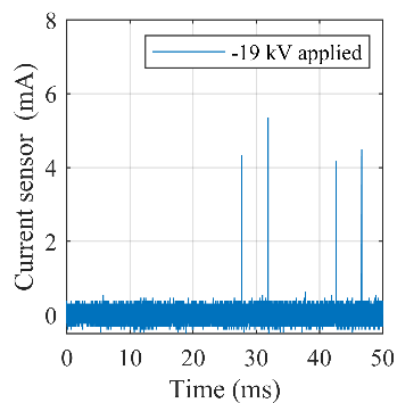

(c)

Figure 9. Positive corona pulses in a 50-ms time window. (a) $-10 \mathrm{kV}$; (b) $-15 \mathrm{kV}$ (c) $-19 \mathrm{kV}$. 
Pictures of the three different stages of corona are presented in Figure 10. In (a), when $-10 \mathrm{kV}$ is applied, we observed filamentary streamers forming the corona in a conical shape. In (b), streamers are slightly larger and more intense, however, it is possible to identify that they are formed from an onset glow at the tip. In (c), the streamers are barely perceptible, and the tiny glowing spot is formed on the tip of the rod. This stage (for applied voltages between around $-14 \mathrm{kV}$ and $-19 \mathrm{kV}$ ) is a transition between the burst pulse stage and the glow corona stage. At $-19 \mathrm{kV}$, when the corona discharge is pulseless, the glow corona is established.

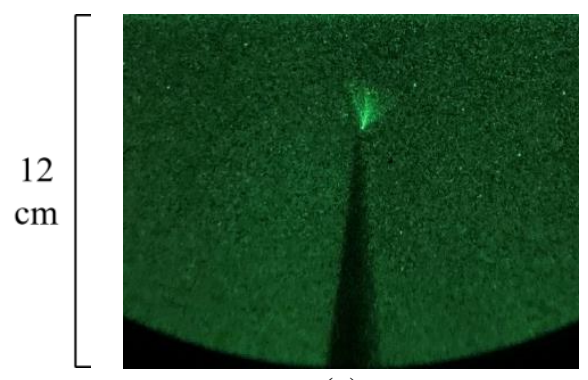

(a)

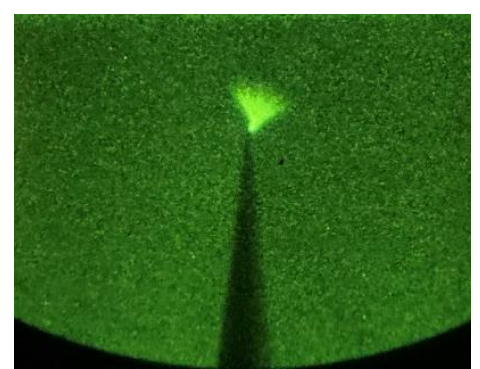

(b)

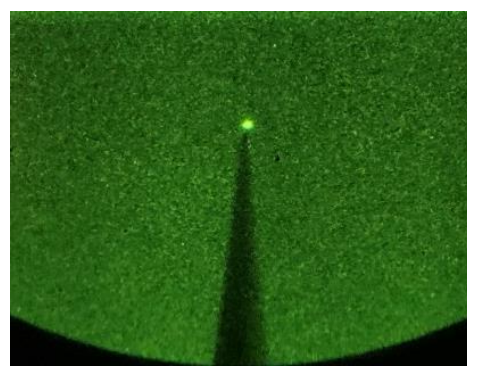

(c)

Figure 10. Positive corona shape. (a) $-10 \mathrm{kV}$; (b) $-15 \mathrm{kV}$; (c) $-19 \mathrm{kV}$.

\section{Field experiment}

For the outdoor experiment, we installed the current transformer tested in the laboratory over a shelter in La Tossa d'Alp, near the Eagle Nest Tower, in the Spanish Pyrenees ( $2525 \mathrm{~m}$ above the sea level), where there is also a system for measuring currents of lightning impacts at the tower. Figure 11 shows the shelter, the tower and a refugee, $250 \mathrm{~m}$ far from the shelter, where the potential gradient was measured using an electric field mill. The measurements of the ambient electric field do not correspond to the local electric field at the tip of the grounded rod, nonetheless, they represent the increase in the electric field in the given environment, which can lead to local enhancements for different structures in the vicinity.

The corona current sensor was coupled to the conductive rod placed over the roof of the shelter. The rod is approximately $1-\mathrm{m}$ long, stands $1.5 \mathrm{~m}$ above the roof, and it is the highest structure within a 3-meters radius. We have installed a high-gain flat plate antenna on the roof at about 2.5 meters far from the tip of the rod. The antenna has a time constant of 0.56 second and a lower cutoff frequency of $0.28 \mathrm{~Hz}$. The signals of current and electric field variation were sampled at $20 \mathrm{MHz}$ using a digitizer.

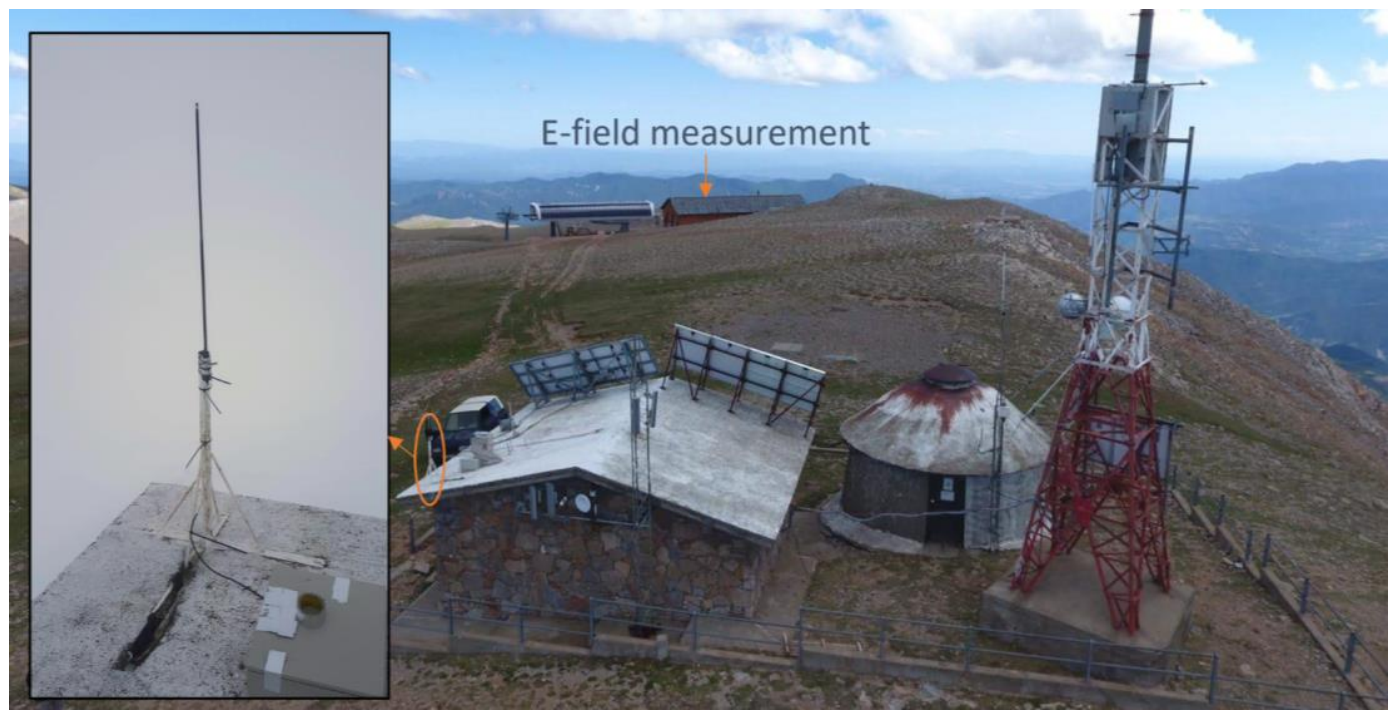

Figure 11. Eagle Nest Tower installations in La Tossa d'Alp, Spain. 


\subsection{Typical signals in the field}

Since the system started operating, many events were observed. Each file is recorded in a time window of 200 milliseconds and the acquisition system takes a few seconds to save the data, leading the system to a considerable downtime. For the recordings, the pulse frequency is determined by counting the number of pulses and dividing them by the length of the time window. Figure 12 shows the typical profile of recordings of positive and negative corona pulses in the field, simultaneously with the electric field derivative from the signal measured by the plate antenna. Over the interval considered, a background potential gradient ( $250 \mathrm{~m}$ away from the rod) of $-6.3 \mathrm{kV} / \mathrm{m}$ was measured for (a) and $4.2 \mathrm{kV} / \mathrm{m}$ for (b).
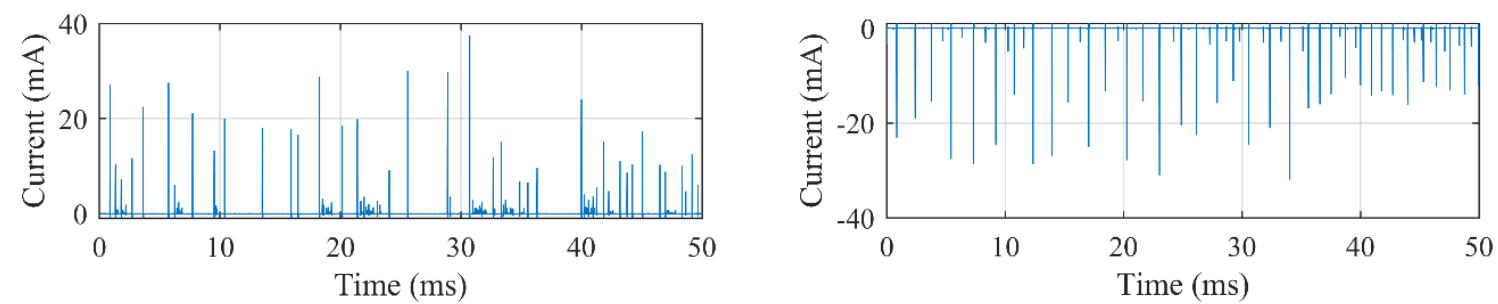

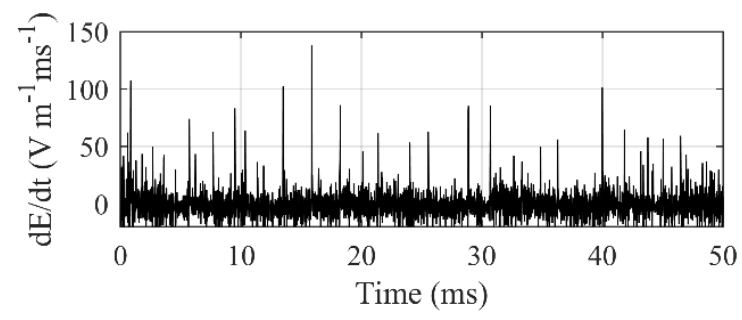

(a)

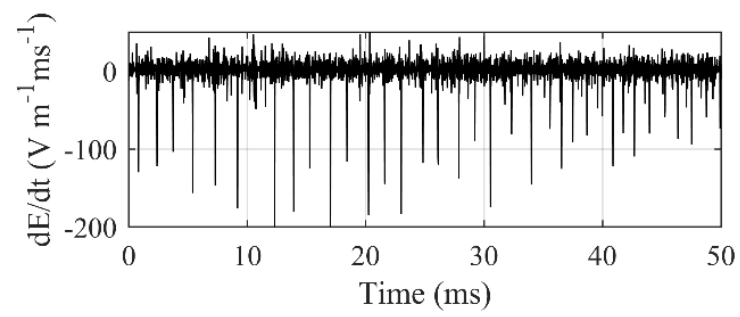

(b)

Figure 12. Typical recordings obtained in field using the current sensor and electric field derivative measured by the plate antenna.

(a) Positive corona; (b) Negative corona.

For the cases shown, an initial high-current pulse (of tens of $\mathrm{mA}$ ) is followed by a train of less-intense pulses in both polarities. The pulses have similar characteristics of rise and fall time compared to pulses observed in the laboratory. Each pulse introduces a perturbation on the local electric field, measured by the plate antenna. In most of the recordings, negative corona pulses present lower amplitude peaks, but when the pulses are very low in amplitude, the change in the electric field is not distinguishable from the noise level of the plate antenna.

We verified whether the electric field pulses could be associated with VHF pulses recorded during the evolution of lightning leaders inside clouds in the proximities of the sensor. For the events shown in Figure 12, the interferometer installed 3-km far from the tower did not register any VHF source for at least 20 minutes before or after the events. This indicates that the changes in the electric field obtained with the flat plate antenna and the current pulses are associated to discharges from the rod.

The corona pulses that we observed presented some similarities with precursor current pulses of artificially triggered lightning. In both cases, the grounded conductors are subject to high background electric field conditions. Biagi et al. (2012) investigated breakdown processes that occur at the top of upward extending wires. Current pulses have peak amplitudes ranging from 1 to more than $100 \mathrm{~A}$, with polarity depending on the electric field. Zhang et al. (2017) studied in detail the features of precursor pulses for positive upward leaders, presenting a time duration in the order of 0.5 to 6 microseconds. The frequency of precursor pulses can be in the range of tens of hertz to tens of kilohertz, and the entire process can last up to 2 seconds, while the wire is being deployed before the lightning strike. 
Comparing these results to corona discharges reported in this work, the peak current and the time duration of precursor pulses are higher, as a consequence of the greater enhancement of the electric field in triggered lightning experiments. Luminosity at the wire tip reveals that precursor pulses can be attributed to aborted leader formations that can extend up to a few meters. The corona discharge is, in turn, related to the inception of streamers over a region that reaches millimeters/centimeters. We believe that corona discharges would also be detected in triggered lightning experiments by employing current sensors sensitive to lower currents, such as the ones we report in this work.

\subsection{Detection of pulses with lightning occurrences far away from the sensor}

The recordings of pulses were processed and for each file, it was assigned the correspondent timestamp and the pulse frequency (amount of pulses divided by time window). Figure 13 depicts an interval of three hours on Aug 29th, 2019, in which the field mill was continuously acquiring data. The increase in the background electric field can lead to recordings of positive and negative pulses.

Positive corona pulses start to be recorded at 17:33 when the potential gradient was approximately -1.8 $\mathrm{kV} / \mathrm{m}$. The highest values of frequency of pulses coincide with peaks in the amplitude of potential gradient indicating a possible correlation between the two quantities. At 17:55, the potential gradient starts decreasing in magnitude and the pulses are no longer observed after 18:15. Its polarity inverts at 18:18, and only a few recordings of negative corona are detected (blue dots) when it reaches its maximum value (around $4 \mathrm{kV} / \mathrm{m}$ ). For the same value of potential gradient, negative corona pulses present a frequency about 2.5 times higher than the frequency observed for positive corona pulses.

At around 19:23, another inversion of polarity and increase in magnitude leads to recordings of positive corona pulses. The reported potential gradient signature is correspondent to the period of end-of-storm oscillation (Moore et al., 1977), in which the electric field at the ground beneath decaying thunderstorms presents several polarity changes during the transition from foul weather to fair weather.

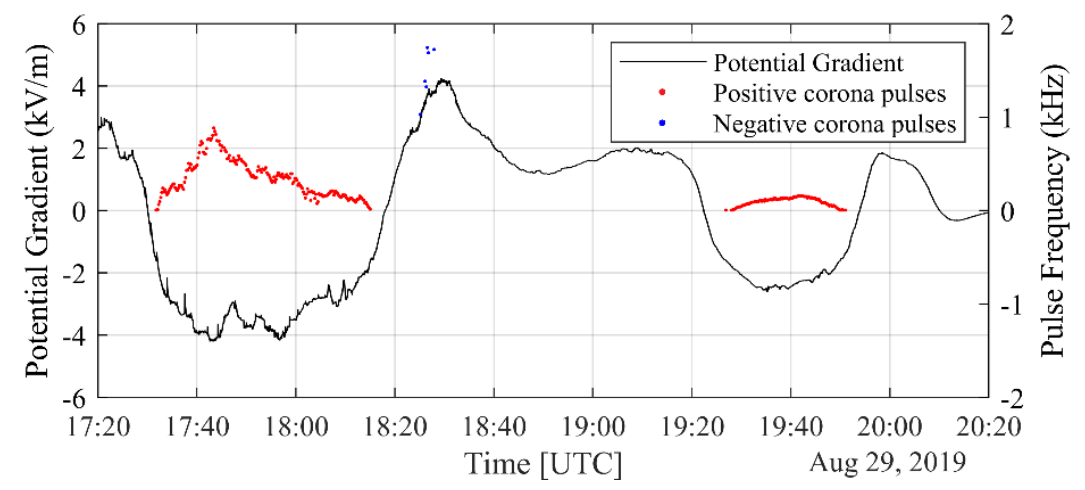

Figure 13. Corona pulses detections when no lightning impacts were registered nearby

Using data from the VHF interferometer, we verified storm activity in the vicinity of the sensor for the same period, as it is illustrated in Figure 14, in a large square area with side length equals to $60 \mathrm{~km}$. The current sensor is positioned at the coordinates $(0,0)$. From the lightning location system (LINET) data, the nearest lightning strike to the sensor was $14 \mathrm{~km}$ away from it, at 17:58. In the first hour shown, VHF sources are detected in the vicinity of the sensor. They are related to leader processes of lightning that can extend over a wide area. From the potential gradient shown in Figure 13, these lightning strikes produced very small perturbations in the electric field, and the characteristic step signature is difficult to be distinguished.

As time increases, the core of the storm moved away from the sensor. At 18:30, the signals from VHF were registered at about $30 \mathrm{~km}$. With LINET, we observed that lightning strikes were $65 \mathrm{~km}$ far from the sensor 
at 20:20. Despite the movement of the storm, pulses were still observed until 19:50, suggesting that the increase in the potential gradient caused by the electrified cloud is enough for corona occurrence.

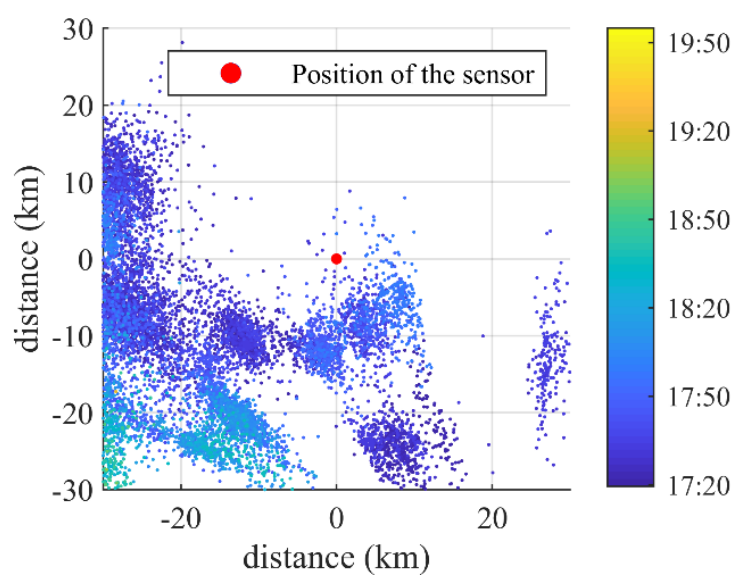

Figure 14. VHF sources near the sensor site for the period shown in Figure 13.

\subsection{Detection of pulses during lightning activity near the sensor}

Corona pulses were observed for several thunderstorms near the sensor. Figure 15 depicts a 15 -minute interval with several lightning flashes (cloud-to-ground and intracloud) in the $15 \mathrm{~km}$ range of the sensor. We verified from the VHF data and with LINET that the nearest return stroke was registered at 18:31:51.642, 1.4 $\mathrm{km}$ away from the sensor.

Since the field mill provides a measurement of the quasi-static electric field, the steps observed are usually related to all return strokes of a flash, or even different flashes that happened within a short period. Among some remarkable steps, there are numerous other small steps indicating lightning activity of a storm cell developing tens of kilometers away.

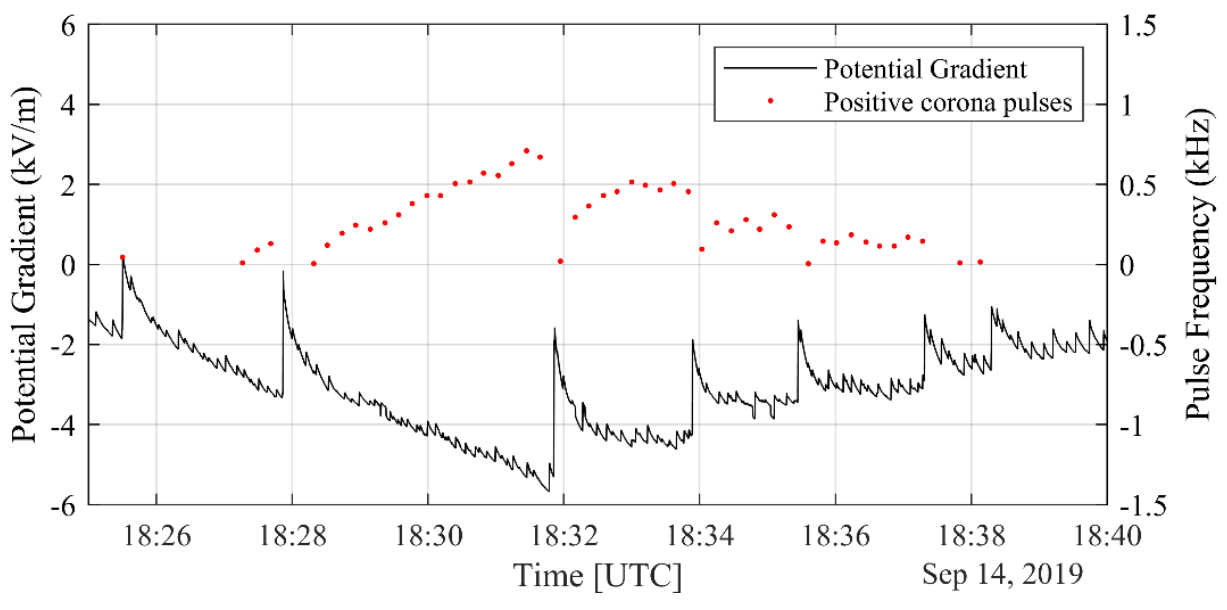

Figure 15. Positive corona detections with lightning activity near the sensor

The potential gradient shown in Figure 15 remains mostly negative. One can note that the strong variations caused by near lightning flashes decrease the magnitude of the electric field, and consequently, the frequency of positive corona pulses. For this event, the highest pulse frequency was around $700 \mathrm{~Hz}$, and it was registered when the potential gradient was close to reaching its peak magnitude (around $5.5 \mathrm{kV} / \mathrm{m}$ ). Figure 16 shows the VHF sources for the period shown in Figure 15, in a square area with a side length of $20 \mathrm{~km}$. One can note that the sources are very dispersed in the vicinity of the sensor during the interval shown. 


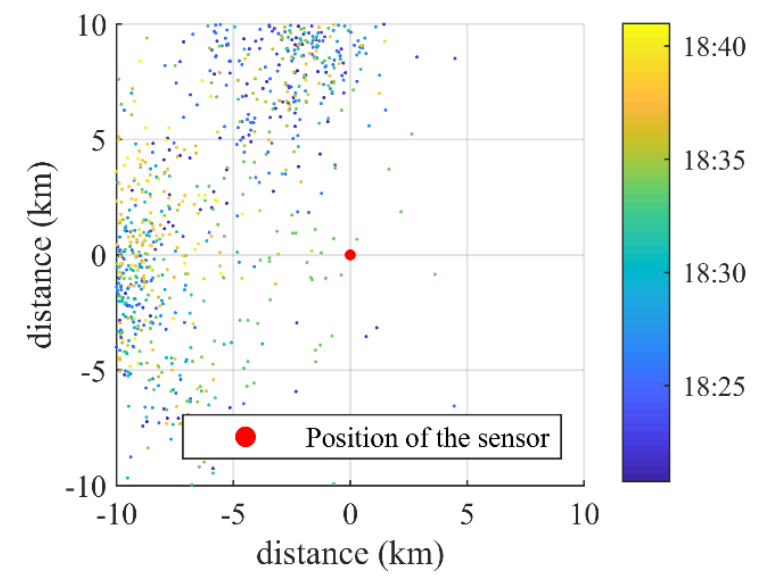

Figure 16. VHF sources near the sensor site for the period shown in Figure 15.

On Sep 15th, 2019, more pulses were recorded in a time window of 40 minutes, as seen in Figure 17. The overview of the potential gradient waveform indicates only one remarkable lightning flash detected at 00:35, reported by LINET as a cloud-to-ground lightning strike 4-km far from the sensor. From the negative step in the potential gradient established by the lightning strike, one can infer that this signature is correspondent to a positive cloud-to-ground strike.

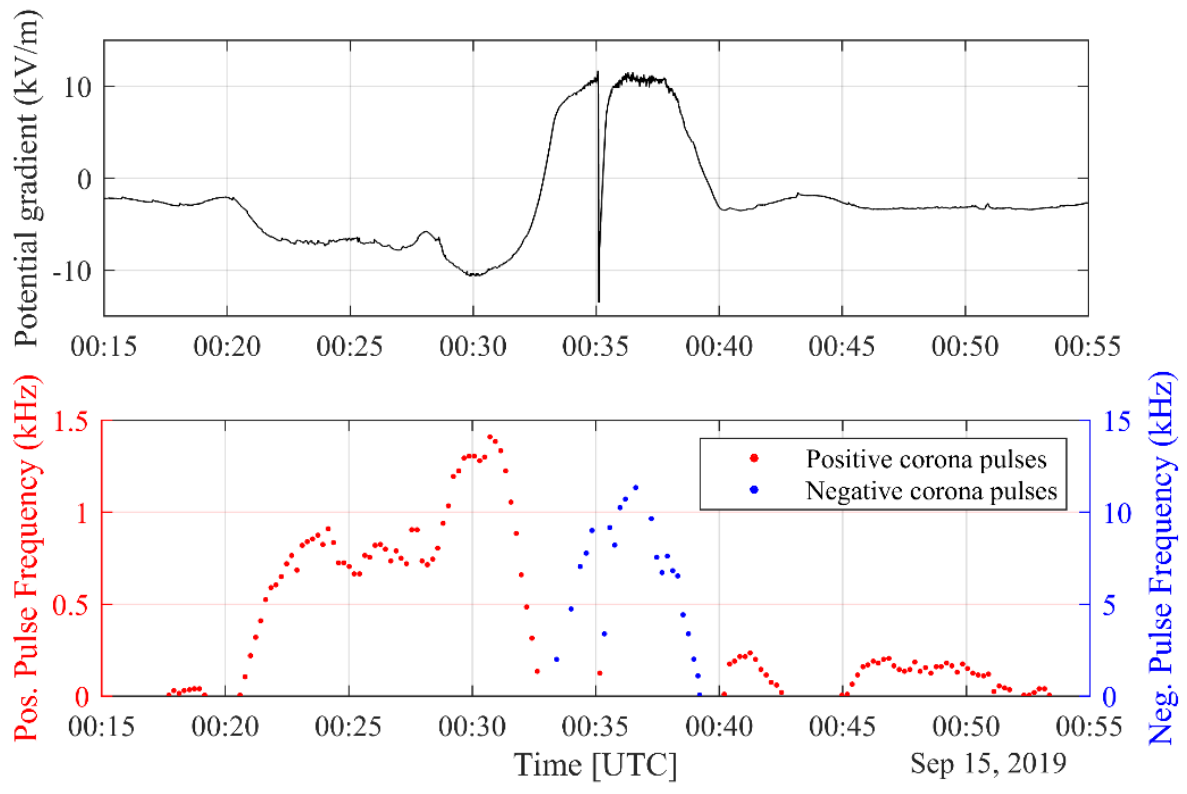

Figure 17. Potential gradient and corona pulses in a 40-minute interval.

Positive corona pulses were detected during most of the time interval shown in Figure 17. At 00:33, the potential gradient inverts polarity and increases, negative corona pulses are recorded. One can note that, for the same level of electric field, the frequency of negative pulses is greater than the one for positive pulses (they are plotted in the same graph with one order of magnitude of difference in scale). This is consistent with our observations in the laboratory. Negative corona pulses also seem to present a certain correlation with the background vertical potential gradient, although we did not have many recordings of them. In addition, they present lower amplitudes, which makes it more challenging to count them among the noise level of the digitizer. 
Figure 18 shows the VHF detections in the vicinity of the sensor and the location of the only lightning strike detected by Linet at 18:35. At that moment, the inversion of the potential gradient causes the inversion of the polarity of pulses, registered by one single file with positive corona pulses. Considering only the data shown in Figure 17, we can estimate the potential gradient for corona onset from the grounded rod. This value is around $-2.5 \mathrm{kV} / \mathrm{m}$ for positive corona and $3.8 \mathrm{kV} / \mathrm{m}$ for negative corona. The correlation between the electric field intensity and corona pulse frequency will be assessed in more detail in the following section.

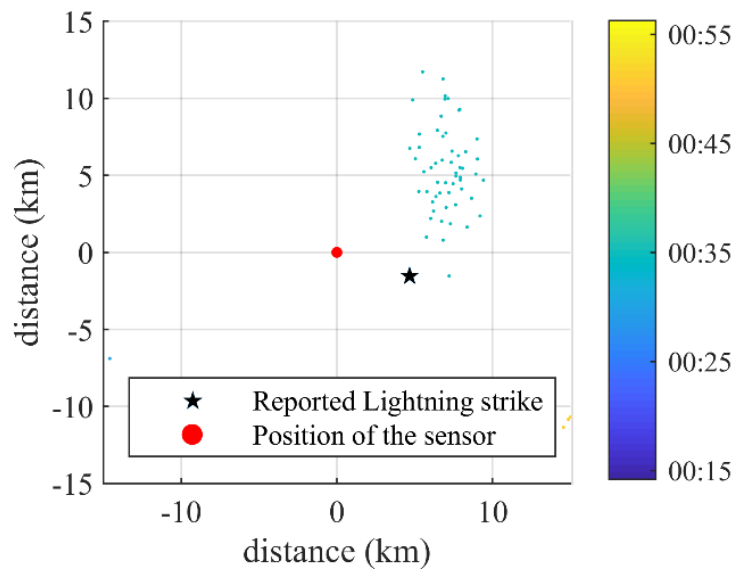

Figure 18. VHF sources near the sensor site for the period shown in Figure 17.

\section{Discussion}

For the setup investigated in the laboratory, the background potential gradient between the two plates for corona onset was $10 \mathrm{kV} / \mathrm{m}$ (positive corona) and $8.2 \mathrm{kV} / \mathrm{m}$ (negative corona). The use of the plane-to-point configuration provides an enhancement of the electric field near the sharp tip of the grounded rod, reaching local levels expected to be in the range of megavolts per meter (Morrow, 1997; Lu et al., 2017), sufficient for ionizing a microregion near the tip and producing the discharges.

Qualitative features of positive and negative corona are very similar to those observed in other studies (i.e. Kexin et al., 2015; Wang et al., 2017; Moreau et al., 2018; Wang et al., 2018). For the same applied voltage, positive corona pulses have higher amplitudes and lower frequency in comparison to negative corona pulses. However, their average current is very similar, in the order of a few microamps, with the precise value depending on the configuration of the geometry of the rod, gap length, presence of wind and several other factors.

\subsection{Laboratory and Field experiments}

The sensor in La Tossa d'Alp recorded corona pulses, even when lightning activity was observed very far from the region, or not observed at all. Thereby, places located in high mountains are susceptible to corona effects due to the proximity of charged clouds and the consequent increase of the ambient electric field.

From the data points obtained for positive corona pulses, pulse frequency varies from 0 to $1.4 \mathrm{kHz}$ with the measured background electric field, which ranges from $1.8 \mathrm{kV} / \mathrm{m}$ to about $12 \mathrm{kV} / \mathrm{m}$. Higher pulse frequencies are associated with higher electric field levels. In the following section, we discuss in more detail the correlation between the two quantities. It is important to ponder that the electric field measurement was performed at a similar height of the installation of the current sensor, but $250 \mathrm{~m}$ away, on a roof of a ski refugee nearby. Since charged clouds can extend horizontally up to a few kilometers, the measurement, performed at such distance, gives representative values for the studies conducted in this work, nevertheless, measurements closer to the sensor could provide an improved correlation. Even with different setups, the values that we report 
are comparable to the ones obtained by D'Alessandro (2009) that reported a threshold of $1.2 \mathrm{kV} / \mathrm{m}$ for positive corona at low wind speeds.

If we compare the frequency of positive pulses obtained in the laboratory (Figure 8) with the values obtained in the field (Figure 13, 15 and 17), we did not observe in the field a reduction in the pulse frequency for higher electric fields. Although the required electric field enhancement may happen for a very short time during close lightning strikes, we speculate that in the laboratory, the configuration of two plates and the grounded rod provides an increase of electric field that is not comparable to the condition of the rod under the ambient electric field. In this way, the current measured in the field is correspondent to the initial stage of corona discharges (burst pulses and Trichel pulses), and for reaching a steady-state glow corona regime, a higher background electric field would be required for a longer period.

Negative corona was more difficult to observe in the field. Due to their lower amplitude, they were more difficult to count among the noise level of the sensor. The lowest electric field observed for their detection was $3.8 \mathrm{kV} / \mathrm{m}$. From his experimental results, D'Alessandro (2009) showed a threshold of $1.5 \mathrm{kV} / \mathrm{m}$ for low wind speeds. Evidently, rod geometry, rod height, and the conditions of the installations play a crucial role in these values, making it difficult to compare electric field thresholds for different experiments.

Regarding the pulse frequency from the measured data, one can note that for higher magnitudes of potential gradient, the pulse frequency differs in almost one magnitude for the different corona polarities. For a potential gradient with a magnitude of around $-12 \mathrm{kV} / \mathrm{m}$, positive corona has a pulse frequency of about 1.3 $\mathrm{kHz}$, whereas for the same magnitude but positive, the pulse frequency can reach around $11 \mathrm{kHz}$, with some dispersion (see Figure 17). This is consistent with our observations in the laboratory for the pulsating stage of corona, in which a $12 \mathrm{kV} / \mathrm{m}$ average electric field leads to pulse frequencies of $1.3 \mathrm{kHz}$ and $8 \mathrm{kHz}$, respectively for positive and negative corona.

\subsection{Dependence on wind speed}

In Figure 19, we present three subplots containing the data points obtained in the events discussed in this paper, according to the date of occurrence. D'Alessandro (2009) showed that for the same electric field level, higher wind speeds result in the increase of the corona current magnitude. In our experiments, we use wind speed measurements performed 370 meters away from the current sensor and verified how the pulse frequency is affected by the average wind speed. Each data point corresponds to a recording of 200 milliseconds of the waveform measured by the current sensor. The pulse frequency is estimated by dividing the number of pulses by the time window, the electric field is the average value computed by the field mill at that timestamp, and the wind speed is the one-minute average registered by the weather station.

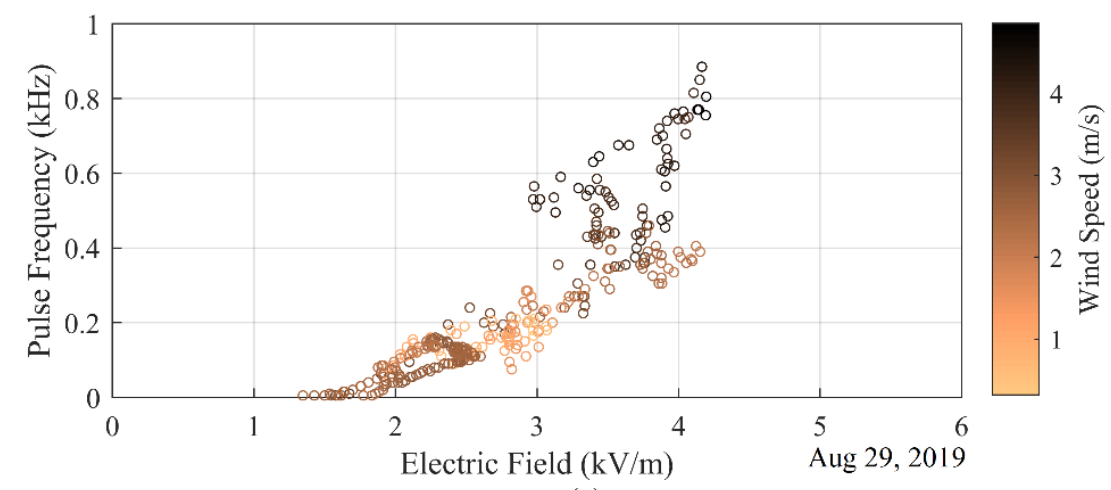

(a) 


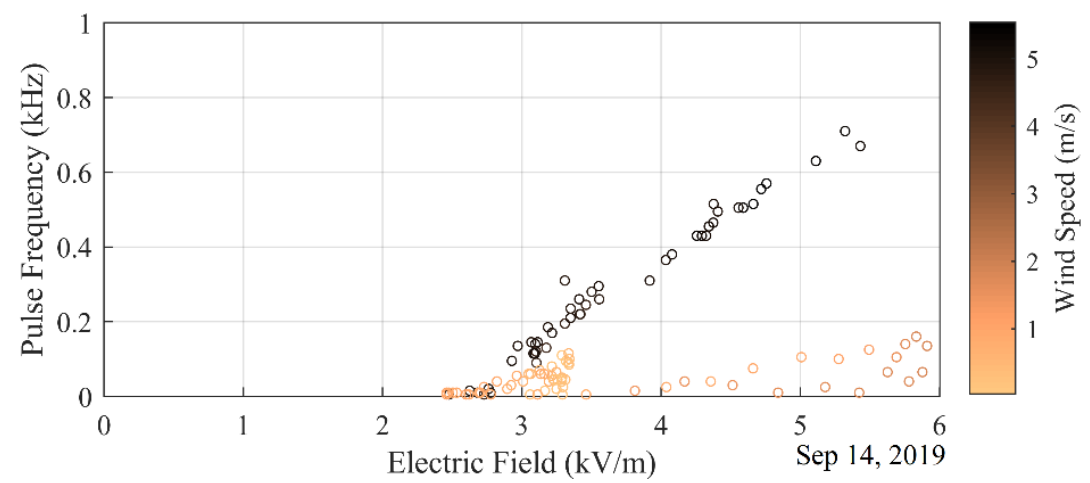

(b)

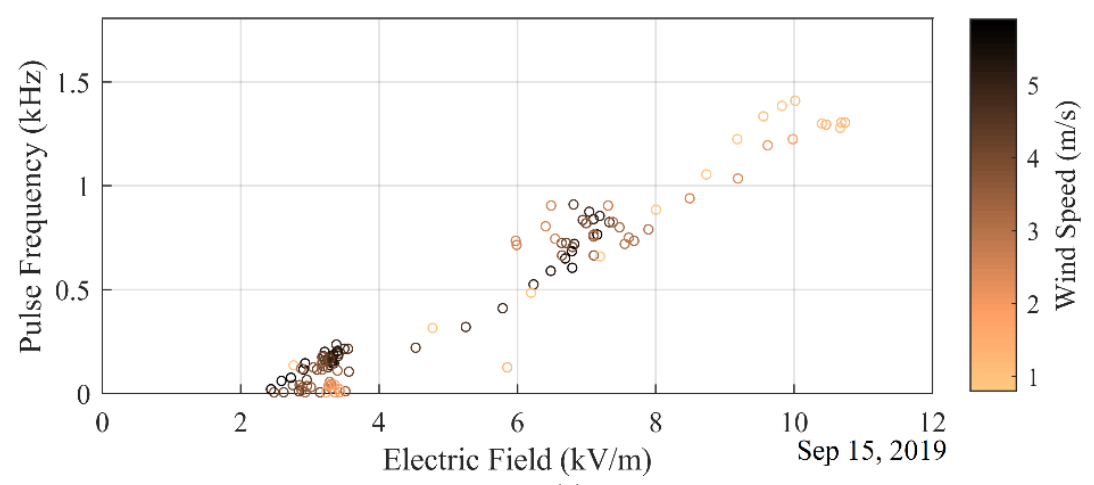

(c)

Figure 19. Scatter plot of pulse frequency versus electric field magnitude for positive corona on (a) Aug 29, (b) Sep 14, and (c) Sep 15.

In Figure 19a, for data from $29^{\text {th }}$ of August 2019, even with the high number of data points displayed, one can note that for a same electric field level, points with higher pulse frequency are correspondent to higher wind speeds. In Figure 19b, we plotted data from two distinct periods. The period with higher wind speed corresponds to the interval shown in Figure 15, and it reveals a trend line with a slope significantly higher from the second period, recorded later, during the same thunderstorm. In the latter case, the electric field ranges from $2.5 \mathrm{kV} / \mathrm{m}$ to $6 \mathrm{kV} / \mathrm{m}$ leading to pulse frequencies inferior than $200 \mathrm{~Hz}$.

The dataset of Sep $15^{\text {th }}$ seems to present a more linear correlation, despite the higher variations of pulse frequency, electric field, and wind speed. One can see a high density of data points in the range from 2 to 4 $\mathrm{kV} / \mathrm{m}$, in which there is a trend showing a higher slope for higher wind speed. For this range, several points with very low pulse frequency are recorded when the wind speed is lower than $2.5 \mathrm{~m} / \mathrm{s}$. For higher electric fields, the small number of points hinders further correlation of data with the average wind speed.

In several other works (Hutchinson, 1951; Chapman, 1955; D’Alessandro, 2009; Bazelyan et al., 2019), it is discussed the quasi-linear dependence of corona current on wind speed above a certain wind speed onset. The results described in section 3 show that for the initial stage of corona discharges both pulse frequency and average current increase with the electric field. The findings presented in section 5 indicate that higher wind speeds can favor corona discharges, increasing the pulse frequency for the same electric field level. The role of wind in removing ions from a space charge cloud acts as a fuel for the corona current and can also favor the initiation of upward leaders. Mostajabi et al. (2018) conducted an analysis on self-initiated upward lightning finding that among a dataset of 31 events, 30 happened under wind speeds higher than $12 \mathrm{~m} / \mathrm{s}$. Very tall structures, that constantly face strong winds, can have the corona shield removed, thus clearing the way for upward leaders (Pineda et al., 2019). 


\section{Summary and Conclusions}

This paper presented observations of corona discharges recorded in the laboratory and in the field using a shunt resistor, a high impedance ammeter and a current transformer.

In the laboratory, several features already reported in literature were confirmed, such as the shape of the pulses and the increase of the corona current according to the voltage applied at the upper plate. In the initial stage of corona, regardless the polarity, the frequency of the pulses increases with the applied voltage. Visual detections using a camera with an optical filter and an intensifier for the UV range allowed observations of the difference in shapes of corona for different polarities and intensities. At the same voltage, positive corona visually develops more than the negative corona, presenting higher amplitudes, lower frequency but with a similar, yet slightly lower, average current.

In the field, we used a current transformer coupled to a conductive grounded rod. Current pulses were measured under high background electric fields. We observed that lightning activity can lead to rapid variations of the electric field, which in turn can trigger, cease, or significantly alter the frequency of corona discharges. A correlation between the frequency of positive corona pulses and the ambient electric field indicated a certain dependency between them. Higher wind speeds may contribute to higher pulse frequencies at the same electric field level. Other factors such as humidity and wind speed are well known to affect the discharges.

We observed some similarities between corona current pulses and precursor current registered for triggered lightning. Despite they present different magnitudes of peak current and time duration, both are caused by wire/electrodes under high electric fields. Corona discharges are related to streamer inception while precursor triggered lightning current is related to aborted leader formations.

This work continues under development, with improved prototypes installed in other two different experimental sites, with different orography than the one considered in this paper. We aim to improve the investigation on the behavior of the corona current, and their relation to the inception of upward leaders associated with lightning strikes.

\section{Acknowledgments}

This project has received funding from the European Union's Horizon 2020 research and innovation program under the Marie Sklodowska-Curie grant agreement No. 722337. This work was also supported by research grants from the Ministry of Economy and Competitiveness (MINECO) and the European Regional Development Fund (FEDER): ENE2017-91636-EXP, ESP2017-86263-C4-2-R and ESP2019-109269RB-C42. 


\section{References}

Aleksandrov, N., Bazelyan, E., Carpenter Jr, R., Drabkin, M., Raizer, Y., 2001. The effect of coronae on leader initiation and development under thunderstorm conditions and in long air gaps. J. Phys. D: Appl. Phys. $34,3256$. https://doi.org/10.1088/0022-3727/34/22/309.

Arcanjo, M., Guimarães, M, Visacro, S. 2019. On the interpeak interval of unipolar pulses of current preceding the return stroke in negative CG lightning. Elec. Power Sys. Res. 173, 13-17. https://doi.org/10.1016/j.epsr.2019.03.028.

Bazelyan, E., Raizer, Y., Aleksandrov, N., D'Alessandro, F., 2009. Corona processes and lightning attachment: The effect of wind during thunderstorms, Atmos.c Res., 94(3), 436-447. https://doi.org/10.1016/j.atmosres.2009.07.002.

Bazelyan, M., Raizer, Y.P., Aleksandrov, N.L. 2015. The effect of space charge produced by corona at ground level on lightning attachment to high objects. Atmos. Res. 153, 74-86. https://doi.org/10.1016/j.atmosres.2014.07.018.

Becerra, M., Cooray, V., Soula, S., Chauzy, S. 2007. Effect of the space charge layer created by corona at ground level on the inception of upward lightning leaders from tall towers. J. Geophys. Res., 112, D12205. https://doi.org/10.1029/2006JD008308.

Becerra, M. 2013. Glow corona generation and streamer inception at the tip of grounded objects during thunderstorms: Revisited. J. of Physics D: Applied Physics, 46, 135205. https://doi.org/10.1088/0022-3727/46/13/135205.

Becerra, M. 2014. Corona discharges and their effect on lightning attachment revisited: Upward leader initiation and downward leader interception. Atmos. Res., 149, 316-323. https://doi.org/10.1016/j.atmosres.2014.05.004.

Biagi, C. J., Uman, M. A., Hill, J. D., Rakov, V. A., Jordan, D. M. 2012. Transient current pulses in rocket-extended wires used to trigger lightning. Journal of Geophysical Research: Atmospheres, 117(D7). https://doi.org/10.1029/2011jd016161.

Chang, J.S., Lawless, P.A., Yamamoto, T. 1991. Corona discharge processes. IEEE Trans. Plasma Sci., 19(6), 1152-1166. https://doi.org/10.1109/27.125038.

Chapman, S. 1955. Effects of wind and space charge on corona point discharge, particularly from aircraft. Proc. Conf. Atmospheric Electricity. Pap. n. 42, AFCRCTR-55-222. 120-134.

Chauzy, S., Raizonville, P. 1982. Space charge layers created by coronae at ground level below thunderclouds: Measurements and modeling. J. Geophys. Res. 87(C4), 3143-3148. https://doi.org/10.1029/JC087iC04p03143.

Chauzy, S., Soula, S. 1999. Contribution of the ground corona ions to the convective charging mechanism. Atmos. Res. 51, 279-300. https://doi.org/10.1016/S0169-8095(99)00013-7.

D'Alessandro, F. 2009. Experimental study of the effect of wind on positive and negative corona from a sharp point in a thunderstorm. J. Electrost. 67, 482-487. https://doi.org/10.1016/j.elstat.2008.12.003.

Davis, R., Standring, W.G. 1947. Discharge currents associated with kite balloons. The Royal Soc. pub. $191,2026$. https://doi.org/10.1098/rspa.1947.0117.

Dordizadeh, P., Adamiak, K., Peter Castle, G.S. 2015. Numerical investigation of the formation of Trichel pulses in a needle-plane geometry. J. Phys. D: Appl. Phys. 48, 415203. https://dx.doi.org/10.1088/0022-3727/48/41/415203.

Dordizadeh, P., Adamiak, K., Peter Castle, G.S. 2017. Experimental study of the characteristics of Trichel pulses in the needle-plane negative corona discharge in atmospheric air. J. of Electrostatics. 88, 49-54. https://doi.org/10.1016/j.elstat.2016.12.013.

Gallo, C.F. 1977. Corona-A brief status report. IEEE Trans. Ind. Appl. IA-13, 550-557. https://doi.org/10.1109/TIA.1977.4503458.

Guimarães, M., Arcanjo, M., Murta Vale, M.H., Visacro, S. 2017. Unusual features of negative leaders' development in natural lightning, according to simultaneous records of current, electric field, luminosity, and high-speed video. J. Geophys. Res. Atmos. 122, 2325-2333. https://doi.org/10.1002/2016JD025891.

Guo, X., Zhang, Q. 2017. Effects of geometrical parameters of two height-unequal adjacent objects on corona discharges from their tips during a thunderstorm. Atmos. Res. 190, 113-120. https://doi.org/10.1016/j.atmosres.2017.02.010.

Harrison, R.G. 2013. The Carnegie Curve. Surv. Geophys. 34, 209. https://doi.org/10.1007/s10712-012-9210-2.

Hutchinson, W.C.A. 1951. Point-discharge currents and the earth's electric field. Quar. J. of the Royal Met. Soc. 77, 627632. https://doi.org/10.1002/qj.49707733406.

Kexin, Z., Yongjun, P., Miao, T., Jingfeng, T., Liqiu, W., Chaohai1, Z. 2015. Mode Transition of Trichel pulses. J. Phys.: Conf. Ser. 652, 012016. https://doi.org/10.1088/1742-6596/652/1/012016. 
Kip, A.F. 1938. Positive-Point-to-Plane Discharge in Air at Atmospheric Pressure. Physical Review. 54(2), $139-146$. https://doi.org/10.1103/PhysRev.54.139.

Lu, B., Sun, H., Wu, Q. 2017. Characteristics of Trichel Pulse Parameters in Negative Corona Discharge. IEEE Trans. on Pl. Sci. 45(8), 2191-2201. https://doi.org/10.1109/TPS.2017.2713831.

Montanyà, J., Van der Velde, O., Romero, D., March, V., Solà, G., Pineda, N., Soula, S., Hermoso, B. 2012. Two upward lightning at the Eagle Nest tower. at Int. Con. on Lightning Protection (ICLP), Vienna, Austria. https://doi.org/10.1109/ICLP.2012.6344373

Montanyà, J., Van der Velde, O., Williams, E. R. 2014. Lightning discharges produced by wind turbines. J. Geophys. Res. Atmos., 119, 1455-1462. https://doi.org/10.1002/2013JD020225.

Mostajabi, A., Sunjerga, A., Azadifar, M., Smorgonskiy, A., Rubinstein, M., Rachidi, F., Diendorfer, G. 2018. On the Impact of Meteorological Conditions on the Initiation of Upward Lightning Flashes from Tall Structures. at 34th Int. Con. on Lightning Protection (ICLP), Rzeszow, Poland. https://doi.org/10.1109/ICLP.2018.8503310.

Moore, C.B., Voonegut, B. 1977. The thundercloud, in Lightning, vol. 1, edited by R. H. Golde, Elsevier, 51-98.

Moreau, E., Audier, P., Bernard, N. 2018. Ionic wind produced by positive and negative corona discharges in air. J. Electrostatics, 93, 85-96. https://doi.org/10.1016/j.elstat.2018.03.009.

Morrow, R. 1997. The theory of positive glow corona. 1997 J. Phys. D: Appl. Phys.30, 3099. https://doi.org/10.1088/00223727/30/22/008.

Pineda, N., Montanyà, J., Romero, D., Bech, J., Casellas, E., Gonzáles, S. 2018. Meteorological aspects of winter upward lightning from an instrumented tower in the Pyrenees. at Int. Con. on Lightning Protection (ICLP), Rzeszow, Poland. https://doi.org/10.1109/ICLP.2018.8503271.

Pineda, N., Figueras i Ventura, J., Romero, D., Mostajabi, A., Azadifar, M., Sunjerga, A., et al. 2019. Meteorological aspects of self-initiated upward lightning at the Säntis tower (Switzerland). J. of Geop. Res. Atmospheres, 124. https://doi.org/10.1029/2019JD030834.

Rakov, V., Fundamentals of Lightning. 2016. Cambridge: Cambridge University Press. https://doi:10.1017/CBO9781139680370.

Trichel, G.W. 1938. The Mechanism of the Negative Point to Plane Corona Near Onset. Physical Review. 54, 1078. https://doi.org/10.1103/PhysRev.54.1078.

Trichel, G.W. 1939. The Mechanism of the Positive Point-to-Plane Corona in Air at Atmospheric Pressure. Physical Review. 55(4), 382-390. https://doi.org/10.1103/PhysRev.55.382.

Wang, Z., Lu, T., Liu, Y., Bian, X., Li, X. 2017. Comparative study of two different measuring methods for corona current pulses. J. Electrost. 88, 134-138. https://doi.org/10.1016/j.elstat.2016.12.018.

Wang, C., Chen, X., Ouyang, J., Li, T., Fu, J. 2018. Pulse Current of Multi-Needle Negative Corona Discharge and Its Electromagnetic Radiation Characteristics. Energies. 11, 3120. https://doi.org/10.3390/en11113120.

Whipple, F.J.W., Scrase F.J. 1936. Point Discharge in the Electric Field of the Earth. Met. Off. of Geo physical Memoirs. 68(7), 20.

Zhang, Y., Krehbiel, P. R., Zhang, Y., Lu, W., Zheng, D., Xu, L., Huang, Z. 2017. Observations of the initial stage of a rocket-and-wire-triggered lightning discharge. Geophys. Res. Lett., 44, 4332- 4340. https://doi.org/10.1002/2017GL072843. 